Color and light are the main factors in the car manufacturing industry, with not much research, conducted on this topic, related to employee physical comfort. The factor affecting employee work comfort is the color factor and lighting time in their workplace environment. Color is the light, reflected by an object, then interpreted by the eye based on the light that hits the object. The value of the color wavelength in the spectrum of $380 \mathrm{~nm}$ to $780 \mathrm{~nm}$ impacts worker performance. Good lighting will affect whether or not the room's light conditions affect the illumination's value. A good working room condition will affect the physical comfort of employees. This research aims to measure and determine the impact of color and lighting at specific color wavelengths on the illumination value and the employee's physical comfort. It starts with studying the color, light, human comfort, then examines the effect on the manufacturing industry employees' performance in the wiring installation assembly industry. Color and light settings are proven essential to get better human comfort. Green color with a wavelength of $490 \mathrm{~nm}$ to 570 can increase the highest illuminate average lux value of $12.43 \%$. Yellow can increase the heart rate by $4.85 \%$, while green can reduce Diastole by $2.95 \%$ and Systole by $1.29 \%$. Pupillary size changes L by $23.17 \%$ and $R$ by $21.43 \%$. The effect of green color and lighting time can increase the value of illumination and decrease heart rate, blood pressure, and pupil size so that it impacts the physical comfort of employees

Keyword: human comfort, manufacture assembly, work station color, level light intensity

\section{INCREASING WORKERS COMFORT: EXPERIMENT OF THE EFFECT OF COLOR AND LIGHTING IN ASSEMBLY MANUFACTURE}

\author{
Iftitah Ruwana \\ Corresponding author \\ Doctoral Student in Mechanical Engineering* \\ Department of Industrial Engineering \\ National Institute of Technology (ITN Malang) \\ Jalan Bendungan Sigura-Gura No. 2, Malang, Indonesia, 65145 \\ E-mail: ruwana.iftitah@gmail.com \\ Pratikt o \\ Professor in Mechanical Engineering \\ Department of Mechanical Engineering* \\ S u g i o n o \\ Doctorate in Industrial Engineering \\ Department of Industrial Engineering* \\ Oyong Novareza \\ Doctorate in Industrial Engineering \\ Department of Industrial Engineering* \\ *Brawijaya University \\ Jl. Mayjend Haryono, 167, Malang, Indonesia, 65145
}

Received date 23.07.2021

Accepted date 25.08.2021 Published date 30.08.2021
How to Cite: Ruwana, I., Pratikto, P., Sugiono, S., Novareza, O. (2021). Increasing workers comfort: experiment of the effect of color and lighting in assembly manufacture. Eastern-European Journal of Enterprise Technologies, 4 (10 (112)), 59-67. doi: https://doi.org/10.15587/1729-4061.2021.239201

\section{Introduction}

In the current issue, human performance becomes an inappropriate competition in the era of globalization. By this fact, the rule of human resources is significant and must be considered by the company to maintain its existence. The emotion and physic should maintain the success and viability of the company, be maintained, and increase the resources with human performance. Good quality conditions will provide comfort and healthy that support human performance and productivity. The Color can be applied by color aspects in the workplace through color games in good wall designs or other equipment. Factors that can influence the comfort conditions of employees in carrying out tasks are external factors and internal comfort as a state of basic human needs that must be fulfilled individually and holistically. Color is a specific spectrum, contained in light. Color identity is determining by light wavelength. The colors wavelength that the human eye can still capture ranges from 380-740 nanometers. Based on researchers, in ones who are in a room blue and green, blood pressure and heartbeat slightly dropped, while in the space, dominated by yellow and red, blood pressure and heart rate can increase. Enough and well-regulated lighting will help create a comfortable and pleasant work environment to maintain excitement in work. One factor that needs to being considered before initiating the selected workspace planning process is the room colour modification. In referring to these conditions, it is necessary to research color effects and lighting to influence the improvement of employees' comfort in work.

\section{Literature review and problem statement}

Companies in the globalization era need to maintain an increase in their employees' resources and work performance [1]. The company must consider supporting its existence to meet employees' needs by keeping employees' physical and mental condition [2]. The company's success and survival are the conditions of employee comfort, especially physical conditions, to maintain and improve resource performance [3]. Performance improvement comes from a process that requires facilities to carry out their activities. According 
to the behavioral management approach, performance results include the quantity, quality, and service, produced by someone. Performance is the ratio between work and the standards, set by the company. In the previous case study, ergonomics creates good, safe, healthy, comfortable, and efficient conditions, especially for the physical environment [4].

The physical environment that has developed can be used for an analysis of human performance based on an ergonomic approach [5]. It is not limited to design and human-centered design, including tools and systems by following human labor. The design of working methods that are compatible with comfort will have a positive impact [6]. Ergonomics factors can provide benefits to organizations regarding the importance of health and environmental conditions at work. The ergonomic approach's main focus pays attention to designing objects, work procedures, and work environments in carrying out work to obtain optimal performance results [7]. Thus, ergonomics significantly affect the design in improving the productivity of human labor to achieve a practical, healthy, safe, comfortable, and efficient one. Color background, lighting, contrasting display resolution can affect the design of the workspace environment. Physical environmental research approaches methods that can affect the human condition, work, and supporting facilities in the hope of preventing the reduction of errors to increase the productivity of human labor to achieve healthy, safe, comfortable, and efficient conditions [8]. Thus, the environmental physic of the workplace is the factor that affects work performance, being around the workers. Color and lighting effects can systematically affect the mood of people, working in the room. The physical work environment, including color, light, air, sound, and music, can affect employees' needs in carrying out their duties [9]. Management of work environment factors that are not adequately designed can significantly impact health, well-being, and performance [10]. Therefore, an excellent physical environment will encourage and improve work performance. The good physical condition of employees will increase productivity, while uncomfortable physical conditions can reduce employee performance. The factor of ergonomic physical environment can measure thermal comfort, color, lighting, noise, and vibration. The role of color and lighting in the work environment is significant to be analyzed further for the workplace in the room. Thus, colour not only affects a person's feelings and mood, but colour can also make the brain react [11]. The excessive light intensity can cause scratches, reflections, extreme shadows, and impaired visibility [12].

The study results concluded that the 15 companies surveyed showed increased in work output between 4-35\%. Therefore, the balance of performance both quality and quantity influences someone behavior, which needs facility to establish the activity $[4,13]$. Low lighting intensity can cause visibility and eye strain. The excessive light intensity can cause scratches, reflections, extreme shadows, and impaired visibility [14]. Accordingly, lighting that is not a good design will cause visual disturbance or fatigue during work. Thus, ergonomics greatly affect the design in improving the productivity of human labor to achieve an effective, healthy, safe comfortable, and efficient one $[15,16]$. The effect of lacking illumination quality will produce an impact, namely:

- eye fatigue, thereby reducing power and work efficiency;

- debilitating psychology;

- complaints about the effects on the eyes area and headaches around eyes;

- damage the eyes and senses of others.
Furthermore: the effects of fatigue will cause a decrease in performance in work, as follows:

- loss of productivity;

- low-quality labor;

- a lot of mistakes;

- increased work accidents [9].

The mood will reach its highest level when the lighting is setting, while the spirit decreases when the lighting is too dark. Color also contributes to a more positive attitude [9]. The visual effect is with background colors and virtual lighting among users of an immersive environment [17]. Adequate lighting allows staff to see things; it is achieved quickly and without unnecessary effort [18]. Good and well-organized lighting can help create a relaxed and friendly working atmosphere to maintain energy. It can be concluded, that the right set of colours and lighting effects on the physiological atmosphere can improve human performance [2, 3, 19]. Thus, Good physical environment will encourage and increase work performance. Conversely, an uncomfortable physical environment will decrease work performance. What distinguishes this research from previous researches is that the study discusses the impact of color and lighting on the value of lux and the physical conditions of employee comfort in the manufacturing industry.

\section{The aim and objectives of the study}

The aim of the study is to measure and determine the effect of color and lighting on the value of illumination and human physical comfort in the workspace in the wiring installation assembly industry.

The objectives of the study to achieve the above aim are formulated as follows:

- to measure the intensity of light, which shows the level of brightness, received due to a light source. Color and lighting can affect the brightness level in the workspace. Good intensity will affect the comfort of the environment;

- to measure the physical condition of employees at work. By configuring color and lighting so that it affects the comfort of employees in the workspace.

\section{Materials and methods of research}

\section{1. The Material}

Based on the research objective, namely measuring and determining the impact of colour and lighting on the value of illumination and human physical comfort in the manufacturing industry, research support materials and tools are needed. To measure and determine the impact of colour and lighting on the illumination value, a configuration material in the workspace is necessary, namely gutters in yellow, green, and dark blue. The effects of color and lighting affect humans as a supplement, which improves human performance [17, 20]. The mood will reach its highest level during lighting, while dark lighting can lower the spirit [21]. Color wavelength, can be seen by the human eye, is between $380-740$ nanometers, including red, orange, yellow, green, blue, purple [22]. The wavelength of the colour, used in this research, is the value of the yellow wave length of $510 \mathrm{~nm}$ to 600 reflectance value of $32.17 \%$ to $65.54 \%$, green colour wavelength is 400 to $500 \mathrm{~nm}$ reflectance value of $6.44 \%$ to $32.17 \%$, dark blue colour wavelength is 610 to $700 \mathrm{~nm}$ reflectance value of $32.15 \%$ 
to $42.87 \%$. With the smallest reflectance value, more colour is absorbed to affect the illumination in the workspace. Red and blue can be expected to trigger significant brain reactions from different colors. Red can increase brain concentration in details, while blue splashes - for creativity. Wavelength can be also used to change one's feelings [23]. Based on research, when someone enters a room painted green, his/her blood pressure drops slightly, his /her heart rate and breathing become weaker. If in the dominant yellow and blue space, blood pressure, heart rate increases. Thus, color not only affects one's feelings and mood, but color can also make the brain react. Good lighting in a workplace is when workers can see objects done easily, without excessive effort, when doing work quickly, accurately, and safely. Thus, color not only affects a person's feelings and mood, but color can also make the brain react [11]. The excessive light intensity can cause scratches, reflections, extreme shadows, and impaired visibility [12].

\section{2. Methods of Research}

The method, used in research, is to conduct a design experiment (DOE) in the manufacturing industry. The stages of expériments conduction include: color and lighting configuration in the works environnement of employées, measuring the illumination value in the configuration, measuring the physical condition of employées at work, including heart rate, blood pressure, and pupillary changes.

The color configuration uses dark blue, green, and yellow. The analysis was carried out in the morning, afternoon, evening, and night lighting. The effect of color and lighting effects are produced in the car electrical installation cable assembly production room. The material, used to configure the fabric color change on the engine gutter is yellow, green, and dark blue; the measurement occurs in the morning, afternoon, and evening. The tools, used to measure in research, include lux meter, blood pressure, penlight. Fig. 1 shows the research process in this article. There are five stages in implementing research that start from preparing materials and tools, implementation and measurement, data analysis to determine the effect of color and lighting on physical human comfort.

The design in this study applies DOE and correlates the regression system to assess physical comfort in an ergonomic work environment. The main reasons for using DOE and regression correlation are reduction of human error, creation of expert knowledge, and interpretation of large amounts of unclear data to achieve the research objectives with standard and identified indicators [3, 4, 24].

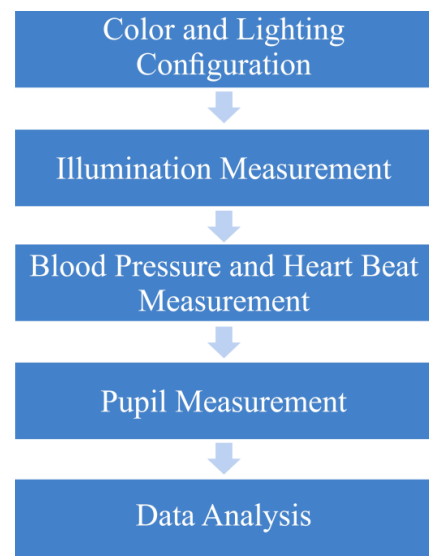

Fig. 1. Research Process

Data analysis use parametric statistical tests, such as the Pearson relationship. Data processing is based on participants, taking part on several occasions. This research aims to design by configuring colors and lighting, which affect human employee comfort physical conditions. Methods and data analysis, used in this research, is to configure color and lighting factors. Take measurements of illumination and blood pressure. Measure changes in the right pupil and left pupil. Analysis of research data using the experimental design method (DOE).

\section{Results of the effect of color and lighting on} illumination (lux meter) and human physical comfort

\section{1. The effect of color and lighting on illumination (lux} meter)

Fig. 2 shows a graph of the impact of colour and lighting on the value of illumination in the workspace.with position and time lighting.

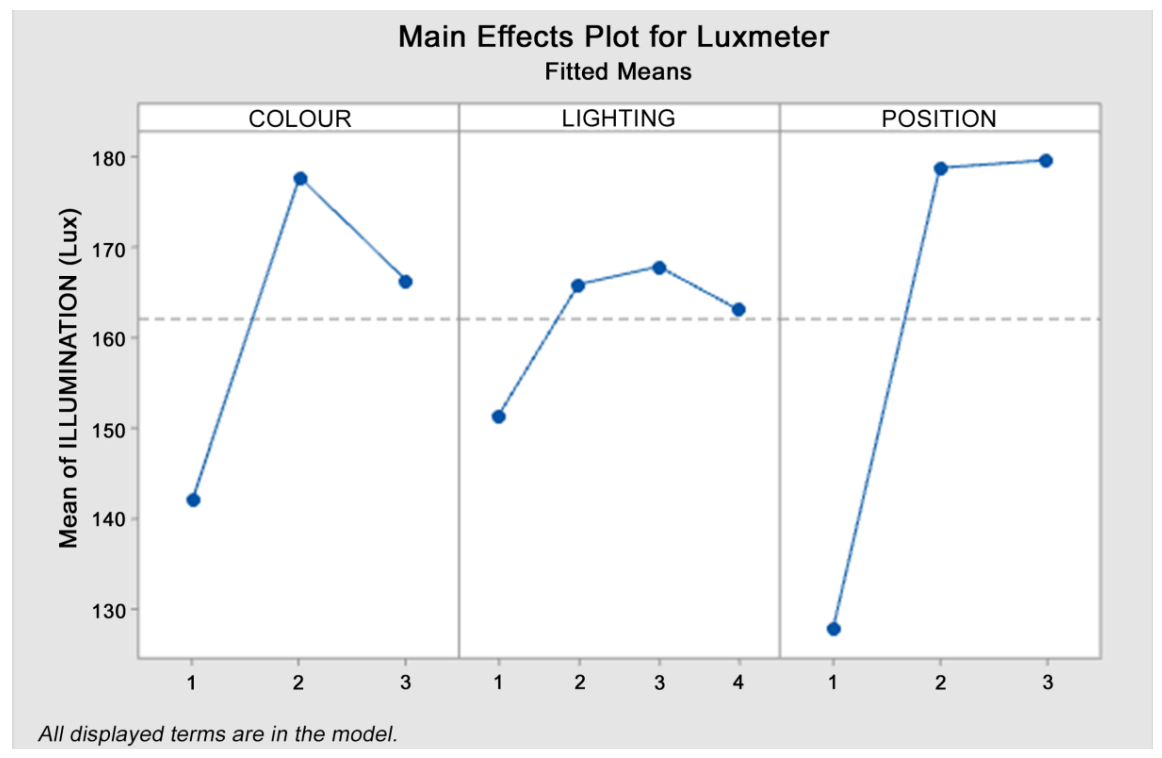

Fig. 2. Color, Lighting and Position on Illumination (Luxmeter) 
The explanation in Fig. 2, the effect of color, lighting, and position of the workspace affects the lux meter's value. Description of picture 3, namely the first color is yellow; the yellow color has an average illumination value of 140.62 lux. The second color is green; the green color has an average value of 177.62 lux. The third is dark blue; dark blue color has an average value of 164.38 lux. The lighting effect on the value of the lux meter is done on the first morning, the second afternoon, the third afternoon, and the fourth night. Measurements in the work area's position are carried out first in the lower place, second in the middle one and the third in the upper position.

Fig. 3 shows a graph of the impact of colour and lighting on the value of illumination (luxmeter).

The effect of color and lighting on the illuminance value will impact employee comfort at work. Good illumination will affect a better workspace so that it affects the physical comfort of employees.

Measurements in the work area's position are carried out first in the lower part, middle, and third in the upper place.

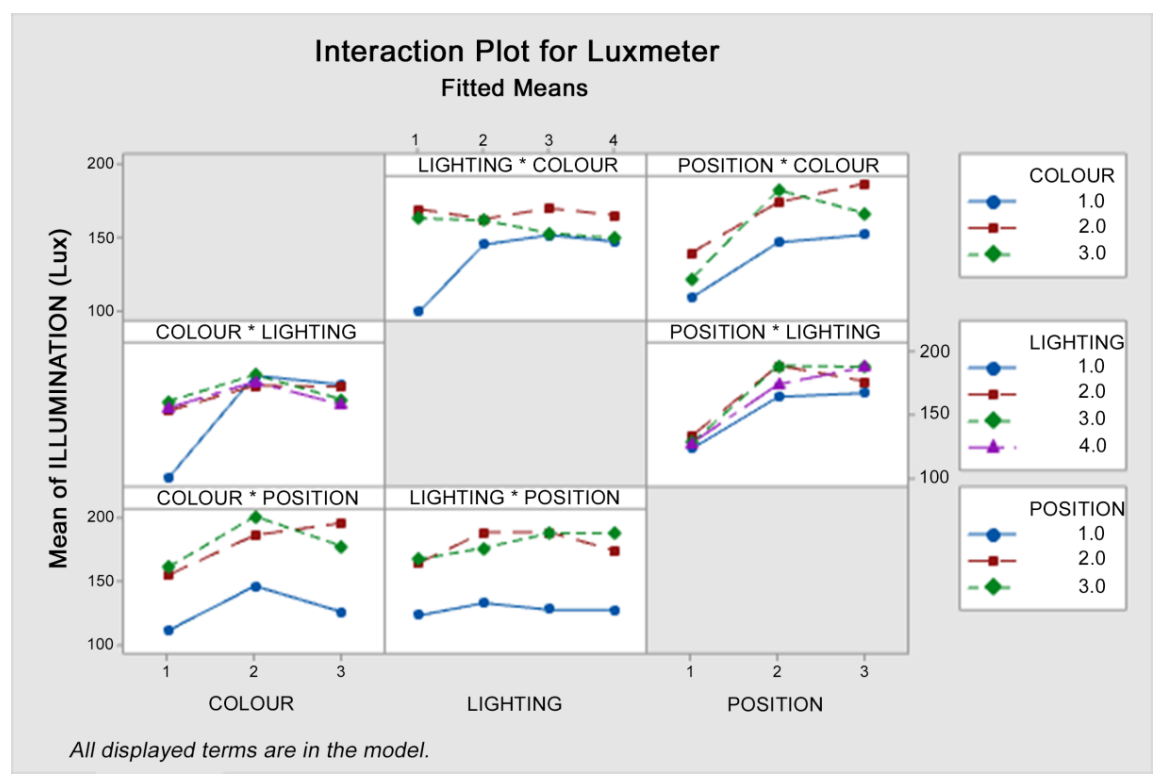

Fig. 3. Effect of color and lighting, position on Illumination Luxmeter
The effect of color and lighting on lux meter values, obtained by measurements of color and morning lighting, yellow has a lower lux meter value than dark blue, green is $4.62 .8 \%$ higher than dark blue from 179.78 lux to 171.84 lux. At day lighting, yellow has a lower lux meter value of $12.08 \%$ than dark blue from 151.70 lux to 170.02 lux, and green is $4.42 \%$ higher than dark blue from 173.00 lux to 170.02 lux. Yellow lighting in the evening has a higher lux meter value of $0.71 \%$ than dark blue from 160.14 lux to 159.00 lux, and green is more elevated from dark blue $12.43 \%$ from181.56 lux to 159.00 lux. Yellow lighting at night has a lower lux meter value of $0.31 \%$ than dark blue, from 154,88 lux to 155.36 lux, green is higher by $11.79 \%$ than dark blue from 176.14 lux to 155.36 lux.

\section{2. The Effects of Color and Lighting on Human Physi-} cal Comfort

The research results of the effect of color and lighting configurations on the physical comfort of employees using the DOE method. The measurement of employee comfort is heart rate, blood pressure, and changes in pupil size.

\section{2. 1. The Effects of Color and Lighting on Heart Rate}

The heart rate condition will affect the employee's physical comfort, one of the factors that influence it is the work environment factor. Color and lighting can affect the comfort of employees in the workspace. The effect of color and lighting on heart rate in Fig. 4.

The explanation in Fig. 4, the effect of color and lighting affects the heart rate value. Description of picture 3 , namely the first color is yellow. The yellow color has an average heart rate value of $92.84 \mathrm{bpm}$. The second color is green; the green color has an average value of $86.52 \mathrm{bpm}$. The third is dark blue; dark blue color has an average value of $87.91 \mathrm{bpm}$.
The impact of green on lux meter values is an increase of $8.30 \%$, of dark blue from 167.62 lux to 170.02 lux. The impact of yellow on lux meter values decreased by $14.26 \%$, of dark blue from 140.61 lux to 164.38 lux. The effect of color on the change in the value of the luxmeter is due to the difference in wavelength in each color under these conditions. Morning lighting lux meter measurement shows the lowest value, while the highest lux meter value occurs in the afternoon lighting measurement. Fig. 3 shows that the lighting measurements were taken at:
1) morning;
2) afternoon;
3) evening;
4) night.

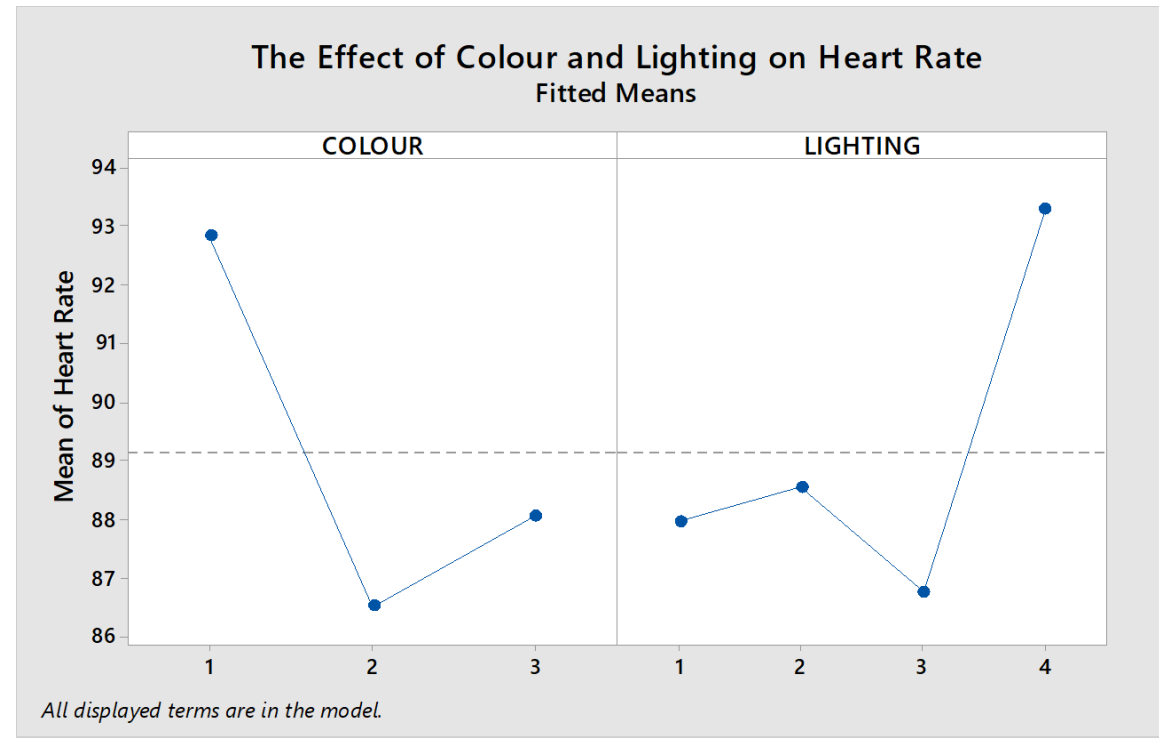

Fig. 4. Effect of color and lighting on heart rate 
Fig. 5 shows employees' heart rates due to color and lighting effects in the room. The use of green gutters can reduce heart rate by $0.97 \%$ compared to using a blue gutter from $87.91 \mathrm{bpm}$ to $86.52 \mathrm{bpm}$. A yellow gutter can increase an employee's heart rate by $4.85 \%$ from $87.91 \mathrm{bpm}$ to $92.84 \mathrm{bpm}$. Lighting in the afternoon with the use of a green gutter is the lowest heart rate of employees. The highest employee heart rate is when the employee works at night using a yellow gutter. When a person is in a room with a blue wall, it will lower the heart rate.

\section{2. 2. The Effects of Color and} Lighting on Diastolic and Systolic Blood Pressure

The effect was examined on the manufacturing industry employees in the wiring installation assembly industry. The color of the gutter, used in the assembly machine, is yellow, green, and dark blue. Lighting is studied in the morning, afternoon, evening, and night. Fig. 6 shows a graph of the measurement of employee's diastolic blood pressure due to the effect of color and lighting in the workspace.

Fig. 6, the effect of color, lighting, and position of the workspace affects the diastole value. Description of Fig. 6, namely the first color is yellow; the yellow color has an average diastole value of $72.04 \mathrm{~mm} \mathrm{Hg}$. The second color is green; the green color has an average value of $72.01 \mathrm{~mm} \mathrm{Hg}$. The third is dark blue; dark blue color has an average value of $74.14 \mathrm{~mm} \mathrm{Hg}$. The lighting effect on the value of diastole is done on the first morning, the second afternoon, the third afternoon, and the fourth night. Employees' diastolic blood pressure has the highest value when working with a yellow color configuration at night lighting.

Fig. 7 shows the systolic pressure at the yellow, green, and dark blue color configurations in the workspace with lighting.

Fig. 7 shows the measurement of employee's systolic blood pressure due to the effect of color and lighting in the room. Description of Fig. 7, namely the first color is yellow; the yellow color has an average systole value of $115.92 \mathrm{~mm} \mathrm{Hq}$. The second color is green; the green color has an average value of $113.66 \mathrm{~mm} \mathrm{Hq}$. The third is dark blue; the dark blue color has an average value of $115.13 \mathrm{~mm} \mathrm{Hq}$.

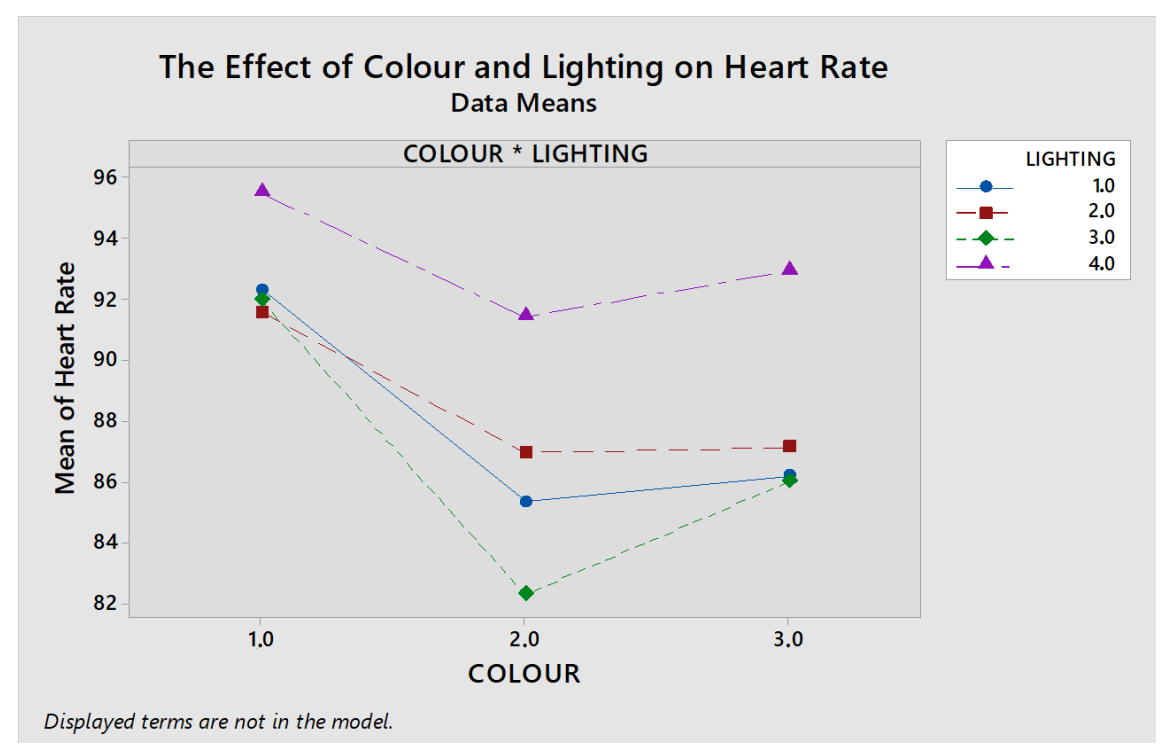

Fig. 5. Impact of Color and Lighting on Heart Rate

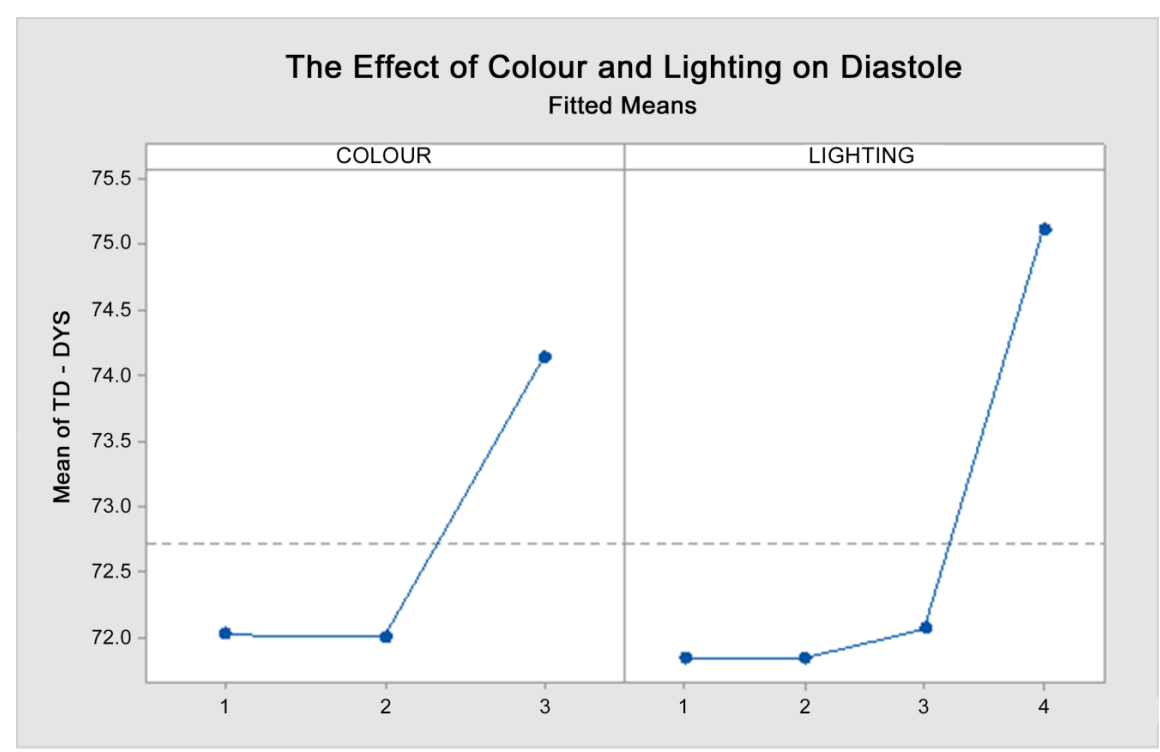

Fig. 6. Effect of Color and Lighting on Diastole

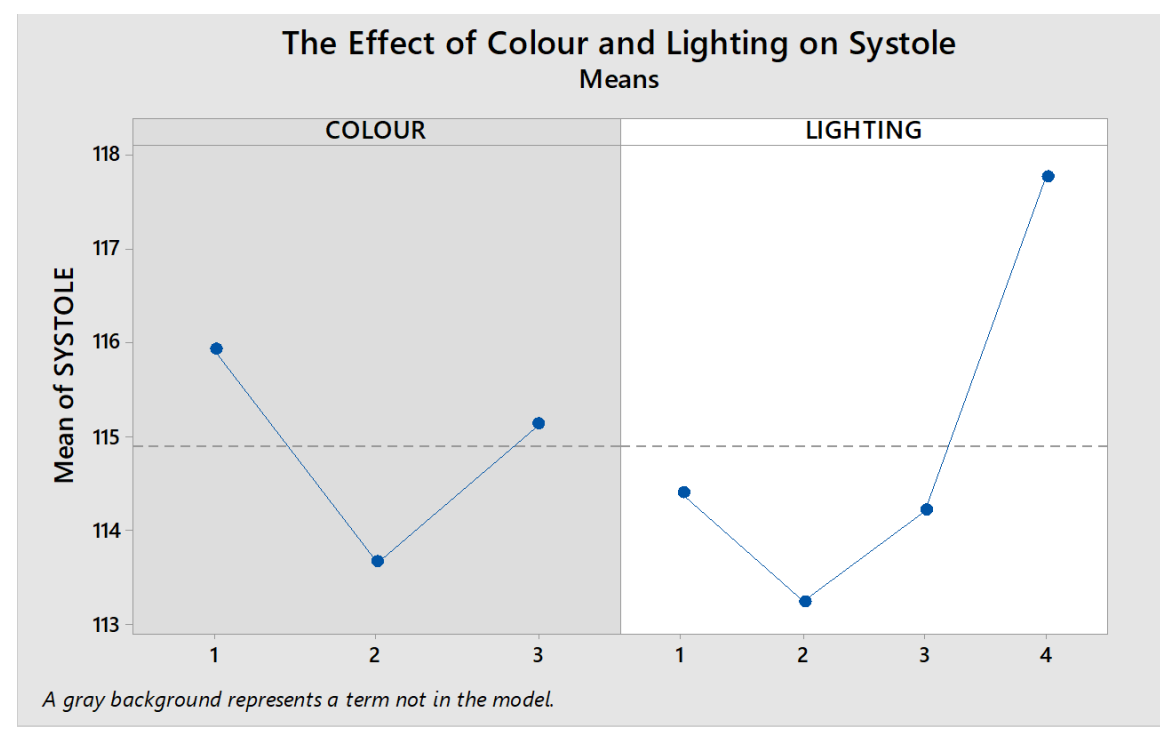

Fig. 7. Effect of Color and Lighting on Systole 
The lighting effect on the value of diastole is done on the first morning, the second afternoon, the third afternoon, and the fourth night. The employee's systolic blood pressure has the highest value when working with yellow night lighting configuration.

Measurement of the effect of colour and lighting on systole in the workspace in Fig. 8 shows that the colour and lighting effect on the systole value will impact employee comfort at work. The high or low systole value will affect the employee's physical comfort condition. Fig. 8 shows the effects of colour and lighting on systole.

The measurement of employee's diastolic and systolic blood pressure due to the effect of color and lighting in the room. A green gutter can reduce diastole by $2.95 \%$ from $74.14 \mathrm{~mm} \mathrm{Hq}$ to $72.01 \mathrm{~mm} \mathrm{Hq}$ and systole by $1.29 \%$ from $115.13 \mathrm{~mm} \mathrm{Hq}$ to $113.66 \mathrm{~mm} \mathrm{Hq}$ comparing with using a blue gutter. A yellow gutter can reduce diastole by $2.92 \%$ from $74.14 \mathrm{~mm} \mathrm{Hq}$ to $72.04 \mathrm{mmHg}$ and increase systole by $0.68 \%$ comparing with using a blue gutter from $115.13 \mathrm{~mm} \mathrm{Hq}$ to $115.92 \mathrm{~mm} \mathrm{Hq}$.

5. 2. 3. The Effects of Color and Lighting on Pupil L and Pupil R

Color and lighting will impact whether or not the workspace is in good condition to affect employee's pupil changes. Bright room lighting tends to shrink pupils, and pupils will widen if the room is not bright enough.

Fig. 9, shows a graph of the impact of colour and lighting on the value of pupil $L$.

In Fig. 9 the effect of color, lighting on the pupil $L$ value is presented. Description of Fig. 9, namely the first color is yellow. The yellow color has an average pupillary changes value of $2.96 \mathrm{~mm}$. The second color is green; the green color has an average value of $2.53 \mathrm{~mm}$. The third is dark blue; the dark blue color has an average value of $2.88 \mathrm{~mm}$. Employees' pupillary changes have the highest value when working with a yellow color configuration at night lighting.

Fig. 10 shows a graph of the impact of colour and lighting on the value of pupil $R$.

Fig. 10 shows effects on employee's pupil $\mathrm{R}$ due to the impact of color and lighting in the room. Description of Fig. 10, namely the first color is yellow; the yellow color has an average pupil R-value of $2.95 \mathrm{~mm}$.

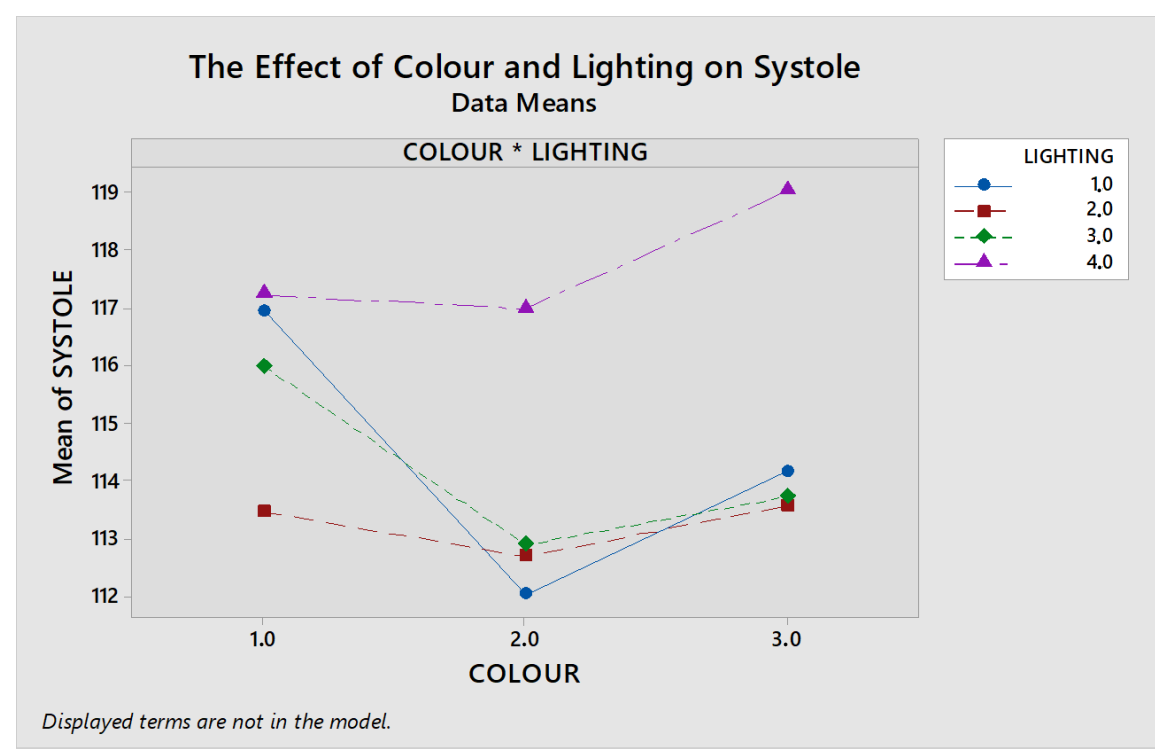

Fig. 8. Graphic Impact of color and lighting on Systole

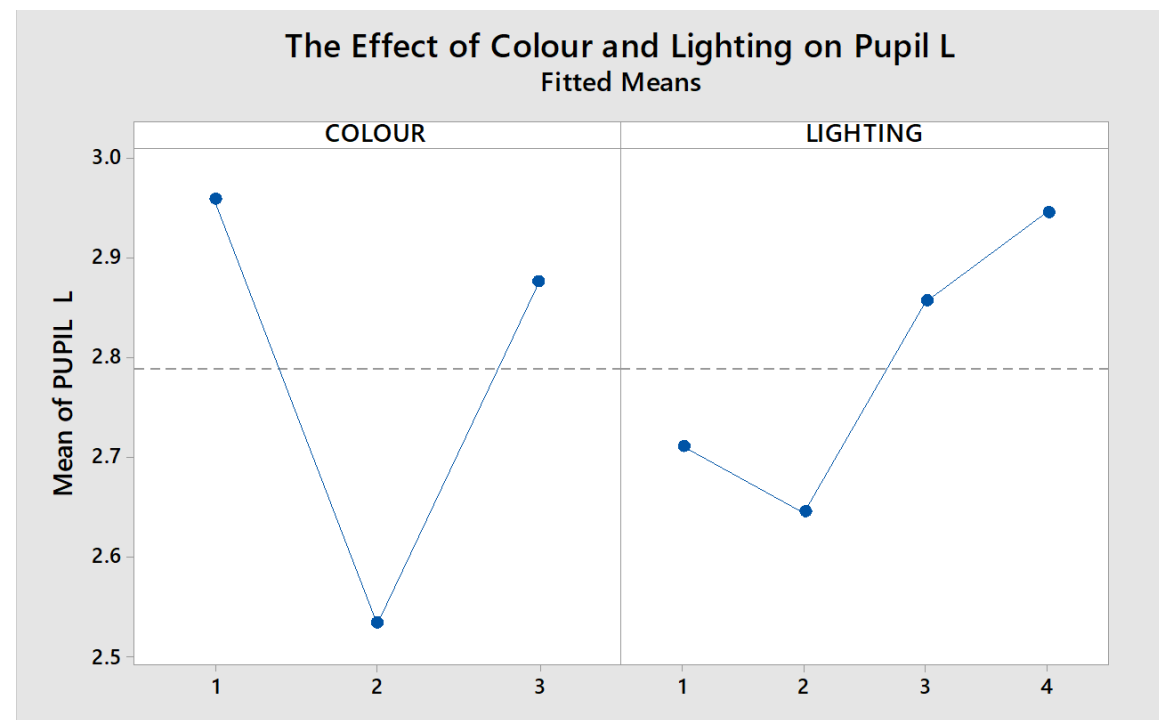

Fig. 9. Effect of Color and Lighting on Pupil L

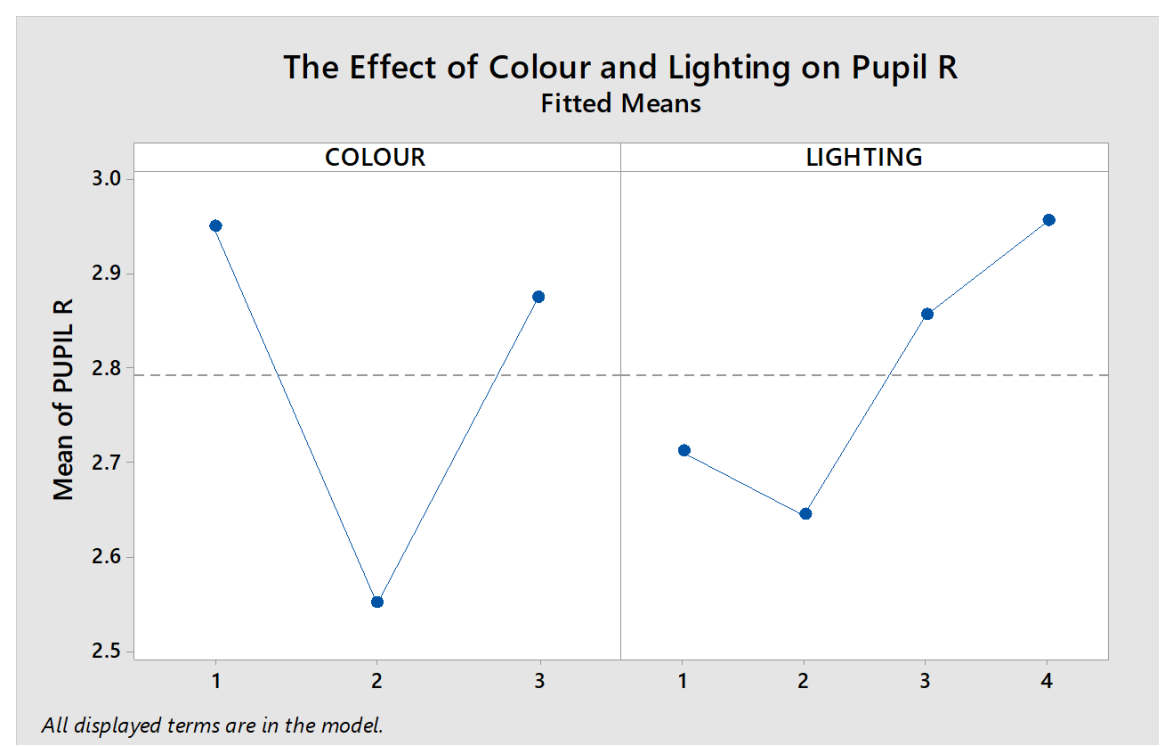

Fig. 10. Effect of Color and Lighting on Pupil R 
The second color is green; the green color has an average value of $2.55 \mathrm{~mm}$. The third is dark blue; dark blue color has an average value of $2.88 \mathrm{~mm}$. The lighting effect on the importance of diastole is done on the first morning, the second afternoon, the third afternoon, and the fourth night. The employees have the highest value on pupil $R$ when working with yellow night lighting configuration.

Fig. 11, 12 shows the measurement of employee's pupil size change due to the effect of color and lighting in the room of the workspace. In Fig. 11, 12, the effects of color and lighting can affect the condition of pupil size changes. The yellow color at night lighting changes pupils $L$ and pupils $R$ by $6.25 \%$, pupil size varies by $0.53 \mathrm{~mm}$ from $2.67 \mathrm{~mm}$ to $3.20 \mathrm{~mm}$. It is more significant than what happens by the effect of dark blue and green.

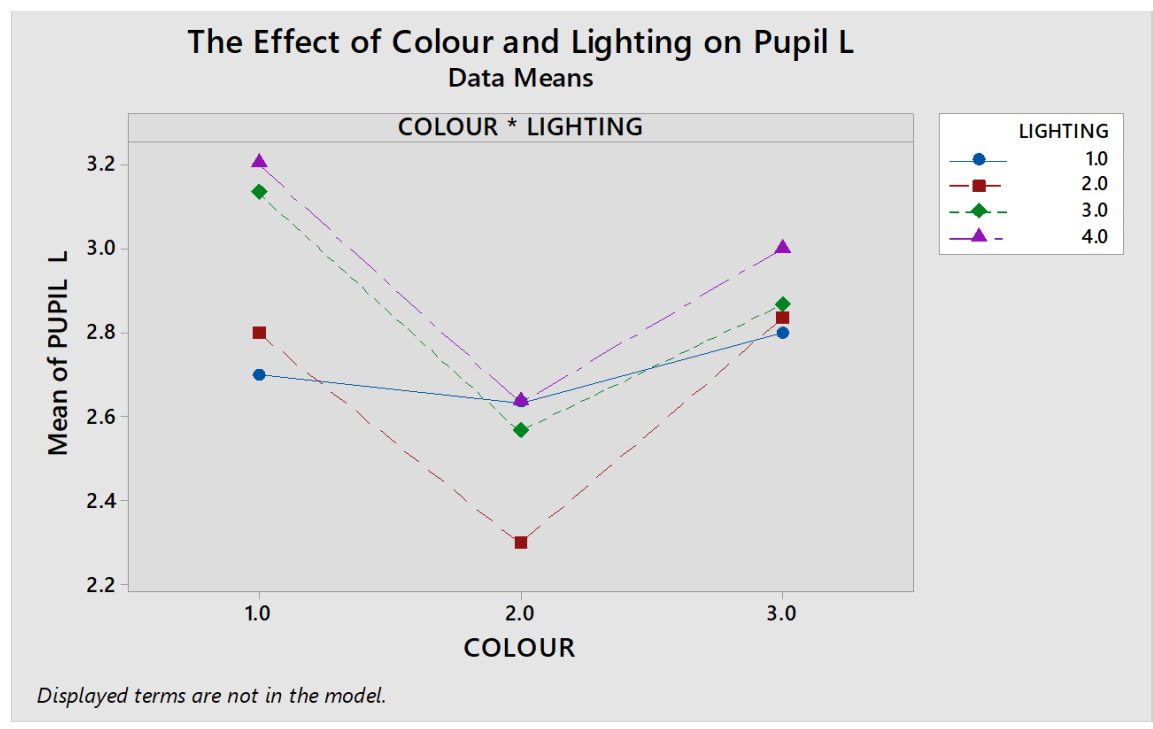

Fig. 11. Effectt of Color and Lighting on Pupil $L$

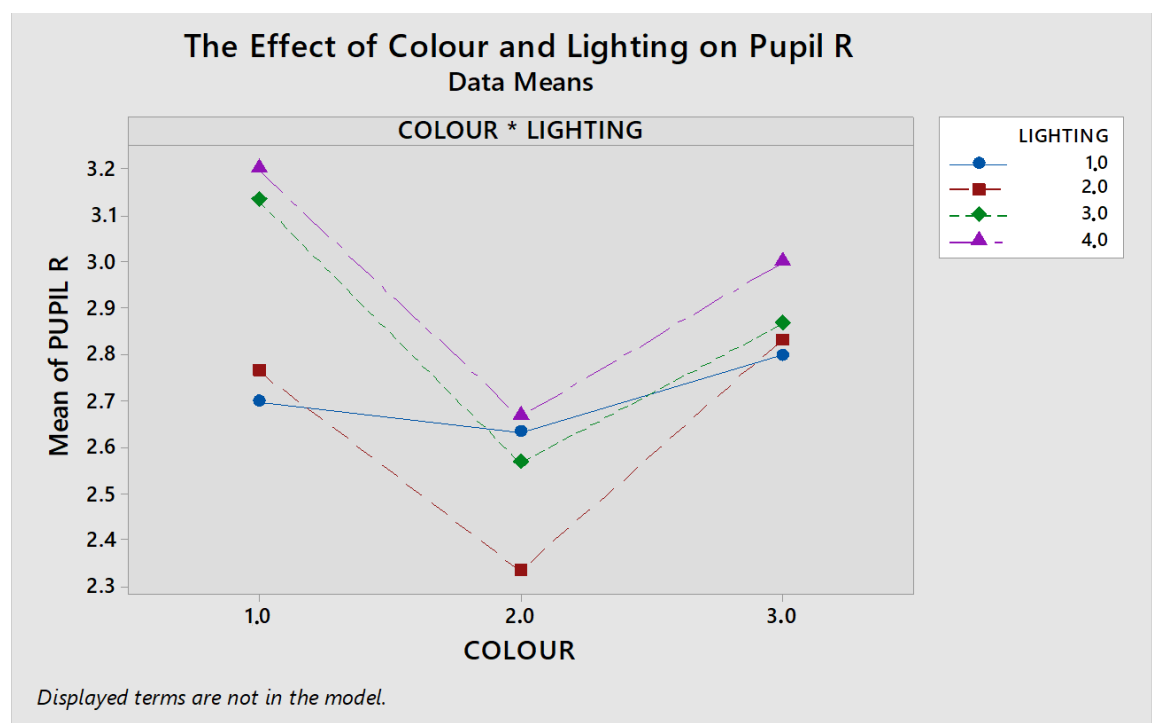

Fig. 12. Effect of color and Lighting on Pupil $R$

\section{Discussion of results of the Effect of Color, Lighting on Illumination (Lux meter) and Human Comfort}

By configuring color and lighting effects, it is possible to determine and select the illumination value and physical comfort conditions of employees. Research using experimental methods can prove whether there is a stronger causal relationship or not when compared to non-experimental research. This study is difficult to generalize because the experimental research conditions are very controlled. The situation is not like actual conditions, which causes the independent variable to appear only on the dependent variable and not by other factors. Experimental research takes a relatively long time. It is necessary to add more factors other than color and lighting in different situations to have a better impact.

The effect of colour and lighting on the value of illumination (lux meter) will impact the physical comfort of employees in the workspace. The colours that influence are yellow, green, and dark blue, the lighting time is in the morning, afternoon, evening, and night. The effect of color and lighting on the illuminance value will impact employee comfort at work. Good illumination will affect a better workspace so that it affects the physical comfort of employees.

The effect of color and lighting at the bottom gutter position on the illumination value decreases the illumination value of $17.71 \%$ from yellow to dark blue and green is increased by $14.03 \%$ of dark blue (Fig. 2,3). The effect of the color and position of the middle work area, obtained by yellow, decreases the lux meter value by $26.61 \%$ from the dark blue color, and the green color decreases by $5.23 \%$ from the dark blue color (Fig. 2,3). The impact of the color and position of the work area for a gutter of the yellow color decreased in the lux meter value of $6.97 \%$ of the dark blue color, the green color is of an increase by $14.41 \%$ of the dark blue color (Fig. 2, 3). From the analysis of the impact of the yellow color configuration and lighting in the morning, afternoon, evening and night there is a decrease in the illumination value, while the green color configuration can increase the illumination value. Illumination measurements at the bottom and middle of the yellow gutter decreased the illumination value, while the green colour increased. Insufficient lighting intensity can cause poor visibility and eye strain. The excessive light intensity can cause scratches, reflections, extreme shadows, and impaired visibility. Good lighting in the workplace can help create a good work environment to work safely and comfortably to prevent fatigue at work, especially fatigue, caused by physical and psychological factors.

Using a green gutter can reduceemployee's heart rate by $0.97 \%$, while the yellow colour can increase employee's heart rate by $4.85 \%$ (Fig. 4, 5). Lighting in the afternoon with the use of a green gutter is the lowest heart rate of employees. The highest employee's heart rate is when the employee 
works at night using a yellow gutter. When a person is in a room with a blue wall, it will lower the heart rate. The highest increase in employee's heart rate occurred in the yellow colour configuration and lighting at night. At the same time, there was a decrease in heart rate in the green colour configuration in the afternoon.

Measurement of the effect of colour and lighting on systole in the workspace testifies that it will impact employee's comfort at work. The high or low systole value will affect the employee's physical comfort condition.

The measurement of employee's diastole and systole blood pressure due to the effect of color and lighting in the room in fig. $6-8$. A green gutter can reduce diastole by $2.95 \%$ from $74.14 \mathrm{~mm} \mathrm{Hq}$ to $72.01 \mathrm{~mm} \mathrm{Hq}$ and systole by $1.29 \%$ from $115.13 \mathrm{~mm} \mathrm{Hq}$ to $113.66 \mathrm{~mm} \mathrm{Hq}$ comparing with a blue gutter. The yellow gutter can reduce diastole by $2.92 \%$ from $74.14 \mathrm{~mm} \mathrm{Hq}$ to $72.04 \mathrm{mmHg}$ and increase systole by $0.68 \%$ comparing with using a blue gutter from $115.13 \mathrm{~mm} \mathrm{Hq}$ to $115.92 \mathrm{~mm} \mathrm{Hq}$. Lighting in the afternoon with the use of a green gutter is the lowest employee's diastole. The highest employee's systole value is by using a blue gutter when the employee works at night. Thus, color can affect blood pressure. Blue and green can lower blood pressure, while yellow can increase blood pressure. Based on previous research, when a person enters a room painted blue, his/her blood pressure drops slightly. If someone is in a predominantly red space, blood pressure will increase. Thus, color not only affects one's feelings and moods, but color can also cause changes in physical conditions.

The measurement of employee's pupil size change due to the effect of color and lighting in the room the workspace. The effect of colour and lighting on changes in left and right pupil size will impact employee's physic comfort at work. The high or low pupil $L$ and pupil $R$ size value will affect the employee's physical comfort condition.

This condition occurs because the pupils work harder. Green color during daytime lighting results in the smallest pupil size compared to the effect of blue and yellow. Size of the pupil L changes by $23.17 \%$, the average pupil size at the green color effect is $2.30 \mathrm{~mm}$ and the pupil size at the blue color effect is $2.83 \mathrm{~mm}$. Size of the pupil $\mathrm{R}$ varies by $21.43 \%$, the average pupil size at the green color effect is $2.33 \mathrm{~mm}$ and the pupil size at the blue color effect $2.83 \mathrm{~mm}$ (Fig. 9-12). The condition occurs due to pupils working more relaxed.

Factors that affect human comfort include the physical comfort of employees at work. The physical work environ- ment, which includes color and lighting factors, can affect work performance. Good colors and lighting will provide physical comfort conditions for employees in the workspace to improve work performance

This research can provide information about developing knowledge about color and lighting configurations for employee comfort in the workspace by providing solutions in designing a comfortable workspace (ergonomic work environment design). This research can contribute to the assembly industry to improve comfort in the work environment.

The research cannot configure the yellow, green, and dark blue colors, so it must develop other colors. The weakness of this research is that it only uses two factors in the study, so it can develop other factors, such as temperature and noise so that employees' comfort in the workspace can be better.

\section{Conclusion}

1. The results of this study have shown that the effect of yellow color and lighting in the afternoon decreased by $12.08 \%$, evening $0.71 \%$ and night $0.31 \%$, while the green color with lighting in the morning increased the illumination value by $4.62 \%$, afternoon $1.75 \%$, evening $12.43 \%$ and $11.80 \%$ at night.

2. This study shows that the human physical comfort, especially employee's heart rate depends on the effect of yellow color that increases it by $4.85 \%$. In comparison, the green color decreased employee's heart rate by $0.97 \%$. The impact of yellow color and lighting on employees' blood pressure it that it reduced diastolic blood pressure by $2.92 \%$, and systolic blood pressure increased by $0.68 \%$. In comparison, green decreased diastolic blood pressure by $2.95 \%$, and systolic blood pressure - by $1.29 \%$. The effect of green color and lighting on the pupil size of employees has a minor decrease with a change in the $L$ pupil of $23.17 \%$, while the in pupil $R$ it is of $21.43 \%$

\section{Acknowledgement}

Our gratitude to the Ministry of Finance, Lembaga Pengelolaan Dana Pendidikan for supporting this research under grant Beasiswa Unggulan Dosen Indonesia (BUDIDN scholarship).

\section{Reference}

1. Ahmadi, M., Zakerian, S. A., Salmanzadeh, H. (2017). Prioritizing the ILO/IEA Ergonomic Checkpoints' measures; a study in an assembly and packaging industry. International Journal of Industrial Ergonomics, 59, 54-63. doi: https://doi.org/10.1016/ j.ergon.2017.03.002

2. Kahya, E. (2007). The effects of job characteristics and working conditions on job performance. International Journal of Industrial Ergonomics, 37 (6), 515-523. doi: https://doi.org/10.1016/j.ergon.2007.02.006

3. Ortiz, M. A., Kurvers, S. R., Bluyssen, P. M. (2017). A review of comfort, health, and energy use: Understanding daily energy use and wellbeing for the development of a new approach to study comfort. Energy and Buildings, 152, 323-335. doi: https://doi.org/ 10.1016/j.enbuild.2017.07.060

4. Jalil, N. A., Yunus, R. M., Said, N. S. (2012). Environmental Colour Impact upon Human Behaviour: A Review. Procedia - Social and Behavioral Sciences, 35, 54-62. doi: https://doi.org/10.1016/j.sbspro.2012.02.062

5. Berger, B. G., Motl, R. W. (2000). Exercise and mood: A selective review and synthesis of research employing the profile of mood states. Journal of Applied Sport Psychology, 12 (1), 69-92. doi: https://doi.org/10.1080/10413200008404214

6. Southern comfort (1983). Nature, 306 (5945), 720-720. doi: https://doi.org/10.1038/306720b0 
7. Asadzadeh, S. M., Azadeh, A., Negahban, A., Sotoudeh, A. (2013). Assessment and improvement of integrated HSE and macroergonomics factors by fuzzy cognitive maps: The case of a large gas refinery. Journal of Loss Prevention in the Process Industries, 26 (6), 1015-1026. doi: https://doi.org/10.1016/j.jlp.2013.03.007

8. Taha, Z., Soewardi, H., Dawal, S. Z. M. (2014). Axiomatic design principles in analysing the ergonomics design parameter of a virtual environment. International Journal of Industrial Ergonomics, 44 (3), 368-373. doi: https://doi.org/10.1016/j.ergon.2013.11.007

9. Küller, R., Ballal, S., Laike, T., Mikellides, B., Tonello, G. (2006). The impact of light and colour on psychological mood: a cross-cultural study of indoor work environments. Ergonomics, 49 (14), 1496-1507. doi: https://doi.org/10.1080/00140130600858142

10. Eljak, S. A., Hassan, H. A., Gorafi, Y. S. A., Mohamed Ahmed, I. A., Ali, M. Z. A. (2018). Effect of fertilizers application and growing environment on physicochemical properties and bread making quality of Sudanese wheat cultivar. Journal of the Saudi Society of Agricultural Sciences, 17 (4), 376-384. doi: https://doi.org/10.1016/j.jssas.2016.09.002

11. Tantanatewin, W., Inkarojrit, V. (2016). Effects of color and lighting on retail impression and identity. Journal of Environmental Psychology, 46, 197-205. doi: https://doi.org/10.1016/j.jenvp.2016.04.015

12. De Korte, E. M., Spiekman, M., Hoes-van Oeffelen, L., van der Zande, B., Vissenberg, G., Huiskes, G., Kuijt-Evers, L. F. M. (2015) Personal environmental control: Effects of pre-set conditions for heating and lighting on personal settings, task performance and comfort experience. Building and Environment, 86, 166-176. doi: https://doi.org/10.1016/j.buildenv.2015.01.002

13. Dianat, I., Vahedi, A., Dehnavi, S. (2016). Association between objective and subjective assessments of environmental ergonomic factors in manufacturing plants. International Journal of Industrial Ergonomics, 54, 26-31. doi: https://doi.org/10.1016/ j.ergon.2015.12.004

14. Bian, Y., Luo, T. (2017). Investigation of visual comfort metrics from subjective responses in China: A study in offices with daylight. Building and Environment, 123, 661-671. doi: https://doi.org/10.1016/j.buildenv.2017.07.035

15. Zainordin, N. B., Abdullah, S. M. B., Baharum, Z. B. A. (2012). Light and Space: Users Perception towards Energy Efficient Buildings. Procedia - Social and Behavioral Sciences, 36, 51-60. doi: https://doi.org/10.1016/j.sbspro.2012.03.006

16. Azadeh, A., Sheikhalishahi, M. (2015). An Efficient Taguchi Approach for the Performance Optimization of Health, Safety, Environment and Ergonomics in Generation Companies. Safety and Health at Work, 6 (2), 77-84. doi: https://doi.org/10.1016/ j.shaw.2014.11.001

17. Bhattacharyya, D., Chowdhury, B., Chatterjee, T., Pal, M., Majumdar, D. (2014). Selection of character/background colour combinations for onscreen searching tasks: An eye movement, subjective and performance approach. Displays, 35 (3), $101-109$. doi: https://doi.org/10.1016/j.displa.2014.03.002

18. Iacomussi, P., Radis, M., Rossi, G., Rossi, L. (2015). Visual Comfort with LED Lighting. Energy Procedia, 78, 729-734. doi: https://doi.org/10.1016/j.egypro.2015.11.082

19. Mikellides, B. (2017). Colour psychology. Colour Design, 193-214. doi: https://doi.org/10.1016/b978-0-08-101270-3.00008-4

20. Boduch, M., Fincher, W. (2009). Standards of Human Comfort. Seminar in Sustainable Architecture. Available at: https://soa. utexas.edu/sites/default/disk/preliminary/preliminary/1-Boduch_Fincher-Standards_of_Human_Comfort.pdf

21. Chellappa, S. L., Steiner, R., Blattner, P., Oelhafen, P., Götz, T., Cajochen, C. (2011). Non-Visual Effects of Light on Melatonin, Alertness and Cognitive Performance: Can Blue-Enriched Light Keep Us Alert? PLoS ONE, 6 (1), e16429. doi: https://doi.org/ 10.1371/journal.pone.0016429

22. Hunt, R. W. G. (2004). The Reproduction of Colour. John Wiley \& Sons. doi: https://doi.org/10.1002/0470024275

23. Gamito, M., Silva, F. M. da. (2015). Color Ergonomic Function in Urban Chromatic Plans. Procedia Manufacturing, 3, 5905-5911. doi: https://doi.org/10.1016/j.promfg.2015.07.901

24. Azadeh, A., Roudi, E., Salehi, V. (2017). Optimum design approach based on integrated macro-ergonomics and resilience engineering in a tile and ceramic factory. Safety Science, 96, 62-74. doi: https://doi.org/10.1016/j.ssci.2017.02.017 